\title{
Maternal uniparental disomy of chromosome 21
}

INSERM

\section{Source}

INSERM. (1999). Orphanet: an online rare disease and orphan drug data base. Maternal uniparental disomy of chromosome 21. ORPHA:96187

Maternal uniparental disomy of chromosome 21 is a uniparental disomy of maternal origin that does not seem to have an adverse impact on the phenotype of an individual. There is a possibility of homozygosity for a recessive disease mutation for which the mother is a carrier and specific phenotype depends on the inherited disorder. 